\title{
POLÍTICA NACIONAL DO LIVRO DIDÁTICO E O ENSINO DE GEOGRAFIA: UM OLHAR SOBRE A FORMAÇÃO CIDADÃ
}

\section{NATIONAL POLICY OF THE TEXTBOOK AND THE GEOGRAFY TEACHING: A VIEW ON CITIZEN FORMATION}

\author{
POLÍTICA NACIONAL DEL LIBRO DE TEXTO Y LA ENSEÑANZA DE LA \\ GEOGRAFÍA: UNA VISIÓN SOBRE LA EDUCACIÓN CIUDADANA
}

\author{
Carina Copatti ${ }^{1}$ https://orcid.org/0000-0003-0485-388X \\ Leonardo Pinto dos Santos ${ }^{2}$ https://orcid.org/0000-0003-2997-1081
}

\begin{abstract}
${ }^{1}$ Doutora em Educação nas Ciências (UNIJUI). Pós-doutora em Políticas Educacionais (UFFS). Licenciada em Geografia e Mestra em Educação (UPF). Professora Adjunta do Departamento de Educação, Política e Sociedade (UFES, Campus Goiabeiras). E-mail: carina.copatti@ufes.br

${ }^{2}$ Doutor em Geografia (UFSM). Mestre em Geografia (UFRGS). Licenciado em Geografia (UFSM) - Professor Adjunto do Curso de Geografia (UFPA, Campus Altamira). E-mail: leonardosantos@ufpa.br
\end{abstract}

\section{RESUMO}

No presente artigo tem-se como objetivo propor reflexões no sentido de identificar de que forma os livros didáticos, no contexto atual, a partir das dinâmicas do Programa Nacional do Livro e do Material Didático (PNLD), tem contribuído ao ensino de Geografia no sentido da formação para a cidadania. Para tanto, alguns aspectos dos editais mais recentes do Programa Nacional do Livro Didático (PNLD 2020, PNLD 2021, PNLD 2023) são analisados afim de perceber quais considerações abarcam a perspectiva da cidadania e que possam contribuir ao ensino escolar de Geografia. Além disso, alguns aspectos referentes ao conteúdo, aspectos metodológicos, qualidade gráfica, de atividades e textos complementares são consideradas, pois compreende-se que são essenciais no processo educativo e para a formação cidadã.

Palavras-chave: Política do livro didático. Ensino de Geografia. Cidadania.

\begin{abstract}
This article aims to propose reflections in order to identify how textbooks, in the current context, from the dynamics of PNLD, have contributed to the teaching of Geography in the sense formation for citizenship. Therefore, some aspects of the most recent notices of the PNLD (PNLD 2020, PNLD 2021, PNLD 2023) are analyzed in order to understand which considerations encompass the perspective of citizenship and which can contribute to the teaching of Geography in schools. In addition, some aspects related to content, methodological aspects, graphic quality, activities and complementary texts are
\end{abstract}


considered, as it is understood that they are essential in the educational process and for the formation process for citizenship.

Keywords: Textbook policy. Teaching Geography. Citizenship.

\section{RESUMEN}

El artículo tiene como objetivo proponer reflexiones para identificar cómo los libros de texto, en el contexto actual, desde la dinámica del Programa Nacional de Libros y Material Didáctico (PNLD), han contribuido a la enseñanza de la Geografía en el sentido de formación para la ciudadanía. Por ello, se analizan algunos aspectos de los avisos más recientes del Programa Nacional de Libros de Texto (PNLD 2020, PNLD 2021, PNLD 2023) para comprender qué consideraciones engloban la perspectiva de la ciudadanía y cuáles pueden contribuir a la enseñanza de la Geografía en la escuela. Además, se consideran algunos aspectos relacionados con el contenido, los aspectos metodológicos, la calidad gráfica, las actividades y los textos complementarios, ya que se entiende que son esenciales en el proceso educativo y para la formación ciudadana.

Palabras clave: política de libros de texto. Enseñanza de la geografía. ciudadanía.

\section{INTRODUÇÃO}

O livro didático enquanto política pública denota distintas interpretações. Constitui-se como um material disponibilizado a todas as escolas do país cadastradas no Programa Nacional do Livro e do Material Didático (PNLD), no intuito de democratizar o acesso a materiais didáticos (livros didáticos, obras literárias, atlas escolar, recursos digitais, etc.) aos estudantes, principalmente das escolas públicas. Além destas, recentemente têm sido disponibilizados materiais para escolas confessionais, comunitárias e filantrópicas sem fins lucrativos que estejam também cadastradas para recebimento das obras. Porém, muitas vezes os livros didáticos são questionados, uma vez que, conforme as propostas que apresentam e a forma como são utilizados em sala de aula, podem restringir a autonomia das escolas e dos seus professores.

Apesar de ser bastante debatido e questionado, entende-se que o livro didático é um recurso que tende a democratizar o acesso ao conhecimento, tendo em vista que, em muitas escolas, não há outros materiais que sirvam de modo mais efetivo como fontes de pesquisa, de informação e na construção de conhecimentos, auxiliando os estudantes e seus professores no processo educativo. Tal situação evidencia a necessidade de outros materiais didáticos de qualidade para o ensino escolar e que os livros didáticos sejam coerentes no intuito de contribuir com a formação dos estudantes brasileiros.

É importante destacar que o Brasil é um país de dimensões continentais e que, para além da simples extensão do seu território, é diverso e desigual. Pode-se, assim, por diferentes 
motivos, identificar críticas contundentes aos livros didáticos por não existir nestes materiais algo habitual da cotidianidade da sala de aula e do contexto de vivência das crianças e jovens que os utilizam. No entanto, nesse Brasil extenso, diverso e desigual são os livros didáticos que chegam a locais onde a internet e outros materiais impressos não chegam com a mesma facilidade. Ou seja, há realidades em que somente o livro didático é disponibilizado como recurso nas escolas e como material de pesquisa aos professores.

Nesse sentido, percebe-se que persiste, ainda, no campo educacional, desconhecimento de tais situações e por vezes, inclusive, falta de empatia com aqueles que mais precisam de recursos como este. Isso é importante para que não se veja o PNLD como um Programa de Estado destinado ao gasto de recursos públicos desnecessários, mas sim, é preciso compreendêlo como uma potente política educacional que visa garantir maior equidade no acesso a uma educação de qualidade.

Considerando isso e procurando estabelecer aproximações entre a política do livro didático e o ensino de Geografia, tecem-se, neste texto, reflexões no sentido de identificar de que forma este material, no contexto atual, a partir das dinâmicas do PNLD, tem contribuído para a formação cidadã. Para tanto, alguns aspectos dos editais mais recentes do Programa Nacional do Livro Didático (PNLD 2020, PNLD 2021, PNLD 2023) são analisados a fim de perceber quais considerações abarcam a perspectiva da cidadania e que possam contribuir ao ensino escolar de Geografia. Além disso, alguns aspectos referentes ao conteúdo, aspectos metodológicos, qualidade gráfica, de atividades e textos complementares são considerados ao pensar sobre o planejamento do professor de Geografia.

O presente artigo é dividido em três momentos, o primeiro relacionado à compreensão das transformações do PNLD enquanto política pública, tomando como aportes alguns autores que pesquisam essa temática e também nossas próprias pesquisas. Em um segundo momento analisam-se aspectos inerentes aos editais mais recentes do PNLD que embasam a produção de coleções didáticas, as quais são submetidas ao processo avaliativo. Posteriormente, estes aportes contribuem a um olhar mais centrado em elementos essenciais de serem analisados pelo professor de Geografia, tanto na seleção de coleções didáticas para uso pelos alunos, quanto com relação às suas contribuições para abordar a cidadania em sala de aula.

O presente texto também se direciona a constituir-se como uma possibilidade de entender o PNLD como uma política pública importante dentro da educação nacional. Claro que este Programa não pode ser privado de críticas, mais ainda pelas recentes transformações 
do mesmo ${ }^{1}$. No entanto, há pontos positivos, principalmente por constituir-se como uma política que busca em algum grau diminuir as desigualdades de acesso a um recorte de conteúdos que passa por uma avaliação criteriosa, contribuindo para a construção do conhecimento de crianças e adolescentes brasileiros.

Vemos, nesse sentido, a proposta provoca a mantermos atenção sobre a qualidade necessária nestes materiais, contribuindo para uma educação laica, gratuita e de qualidade. $\mathrm{O}$ PNLD constitui-se como uma das ferramentas para que essa educação possa existir ao disponibilizar materiais diversos que podem ser adaptados às distintas realidades locais. Entretanto, é necessário a atenção para o fato de que os livros didáticos por si só não farão com que a formação dentro das instituições de ensino seja direcionada para caminhos democráticos e de justiça social, mas podem contribuir para que professores e professoras dos distintos lugares que compõem o Brasil busquem formas de dar significado aos conteúdos escolares, não apenas para debater com os estudantes o que está presente no currículo escolar, mas principalmente para construir uma formação cidadã a partir do ensino de Geografia e também de outros componentes curriculares que compõem a educação básica no país.

Para que isso seja possível, é necessário que continuemos os debates e as pesquisas relacionadas à política nacional do livro didático, sendo este texto uma breve tentativa que não busca encerrar o assunto, mas contribuir com o debate.

\section{A POLÍTICA NACIONAL DO LIVRO DIDÁTICO E AS TRANSFORMAÇÕES DO PNLD AO LONGO DO TEMPO}

O Programa Nacional do Livro e do Material Didático, iniciado em 1985, é tomado como referência no estudo proposto por se referir a um conjunto de medidas que remetem à complexificação da produção de livros didáticos destinados às escolas públicas do Brasil. Este Programa, na década de 1990, ganhou um caráter mais complexo diante do processo de avaliação pedagógica das coleções didáticas, iniciada em 1996. Sposito (2006, p. 22) faz um importante apontamento sobre tal questão, ao afirmar que "a avaliação deve ser feita porque o Estado, com recursos públicos, está adquirindo milhões de livros didáticos para distribuição gratuita na rede oficial de ensino básico e deve aferir a qualidade do produto que compra".

\footnotetext{
${ }^{1}$ Algumas matérias da Carta Capital e do El País Brasil apresentam de forma didática parte do cenário que envolve o governo Bolsonaro e sua relação com os livros didáticos no Brasil. https://www.cartacapital.com.br/educacao/mec-recua-com-alteracoes-no-programa-nacional-do-livro-e-domaterial-didatico/; $\quad$ https://www.cartacapital.com.br/educacao/o-que-esperar-da-primeira-fornada-de-livrosdidaticos-sob-bolsonaro/; $\quad$ https://brasil.elpais.com/brasil/2019/04/06/politica/1554504245 154102.html; https://brasil.elpais.com/brasil/2019/04/04/politica/1554334968_202816.html. Acesso em: 29 de dezembro de 2021.
} 
O movimento de expansão do PNLD foi ampliado a partir da redemocratização do país e se constitui, nas últimas décadas, como um Programa complexo, cujos materiais vão além das coleções de livros impressos destinados às escolas. Segundo informações do site do $\mathrm{FNDE}^{2}$, o Programa Nacional do Livro e do Material Didático (PNLD) compreende um conjunto de ações voltadas para a distribuição de obras didáticas, pedagógicas e literárias, entre outros materiais de apoio à prática educativa, destinados aos alunos e professores das escolas públicas de educação básica do país.

O PNLD também contempla as instituições comunitárias, confessionais ou filantrópicas sem fins lucrativos e conveniadas com o Poder Público. As escolas participantes do PNLD recebem materiais de forma sistemática, regular e gratuita, sendo um Programa abrangente e um dos principais instrumentos de apoio ao processo de ensino-aprendizagem nas escolas beneficiadas. Este Programa, portanto, constitui parte de uma política pública constituída de modo gradativo no século XX, tendo as primeiras ações ainda na década de 1920. No entanto, seu caráter abrangente somente se constituiu na década de 1980, de modo mais efetivo.

A importância da compreensão dos desdobramentos da implementação dessa política leva em consideração a influência destes materiais nos contextos de educação pública escolar e de constituir um dos materiais que mais diretamente chega à população, mesmo que circule apenas entre professores e estudantes. Sendo assim, se constitui, segundo Callai (2016), como um dos únicos materiais didáticos acessíveis aos estudantes brasileiros e possíveis de serem acessados pela maioria das famílias, único recurso de pesquisa e informação que adentra a muitos lares brasileiros.

Tem, assim, um sentido de acesso que se considera democrático, por permitir que um recorte de conhecimento produzido seja disponibilizado para os estudantes e que, seu conteúdo contribua para a sua formação, embora entenda-se que o livro didático ou qualquer outro material que compõe o PNLD não contribui, sozinho, para esse processo. Também é importante salientar que este material didático não é completo, o que requer, sempre, que existam complementações, adaptações e um olhar atento e crítico aos conteúdos propostos.

O Programa Nacional do Livro e do Material Didático, engloba um conjunto de ações que vão desde a construção do edital visando à editoração de propostas didáticas, fases de avaliação, definição dos avaliadores, construção do Guia do Livro Didático, escolha e distribuição dessas coleções, possibilitando que cheguem às escolas, visando, desse modo, contribuir para que o processo educativo ocorra da melhor forma possível. No entanto, sabe-se

\footnotetext{
${ }^{2}$ https://www.fnde.gov.br/index.php/programas/programas-do-livro
} 
das lacunas, fragilidades e necessidades de avanço tanto na qualidade dos livros didáticos quanto com relação à formação dos professores.

A partir de 2017 ocorreram mudanças nesta política pública por meio do Decreto $\mathrm{n}^{\circ}$ 9.099/2017. Algumas das alterações mais significativas foram: inclusão do fornecimento de livros às escolas comunitárias, confessionais ou filantrópicas sem fins lucrativos, distribuição anual de livros didáticos e obras literárias, as obras passam a ser consumíveis para os anos iniciais do ensino fundamental, sendo as coleções construídas em consonância com a BNCC. Ainda, teve início a produção e distribuição de livros para os professores de educação física.

Apesar da importância dos avanços no que tange ao maior acesso a estes recursos nas escolas públicas, observa-se, segundo Gonçalves (2017), a implementação de uma política favorável ao mercado editorial a partir da aquisição de livros pelo Estado, o que vem sendo constante no PNLD. Em outras palavras, o Estado tem sido o maior financiador dos grupos editoriais privados, os quais submetem suas propostas a fim de fornecer coleções didáticas para escolas de todo o país. Tal situação vem sendo questionada e duramente criticada por existirem ainda muitos estereótipos e propostas que não remetem à realidade de cada lugar e em defesa da produção de materiais voltados a cada contexto escolar, portanto, atendendo especificidades e necessidades de cada escola.

Nesse caminho, os livros didáticos no cenário brasileiro, são analisados sob diferentes perspectivas. Estes materiais constituem-se como material didático, porém, são também uma mercadoria, uma vez que possuem alto valor para o mercado das editoras, que encontram no Estado brasileiro o maior consumidor de livros. Tem-se, no contexto de produção e distribuição de livros didáticos, uma política de Estado e não de um único governo (mesmo que existam interferências, principalmente a partir do governo do atual presidente Jair Bolsonaro). Sobre isso, Santana Filho (2017, p. 242) indica que "nas últimas décadas o PNLD alcançou a condição de maior programa de distribuição de Livros Didáticos do mundo, movimentando grandes interesses econômicos, políticos e ideológicos em torno dos livros. E, podemos dizer também, acadêmicos".

Nesse sentido, a política nacional do livro didático ganha corpo e importância dentro de um cenário de país extenso, diverso e desigual. Disponibiliza materiais impressos e digitais, além de obras literárias, as quais, em muitos lugares, são as únicas acessíveis a estudantes e suas famílias, ao mesmo tempo que se subscrevem em um cenário movido pela lógica do capital.

É dentro desta lógica conflituosa que o PNLD deve ser conhecido, analisado e compreendido, no intuito de analisar se pode contribuir para uma formação cidadã dentro das 
escolas públicas. Considera-se tal perspectiva tendo em vista que as escolas públicas brasileiras são os ambientes que recebem o grande contingente de estudantes do nosso país, sendo constituída como espaço de diversidade, de conflitos, de trocas, e onde muitas desigualdades econômicas e sociais estão presentes.

\section{OS EDITAIS DO PNLD E A PERSPECTIVA DE FORMAÇÃO PARA A CIDADANIA}

No presente texto, propõe-se uma análise a respeito do edital do PNLD, sua importância e as mudanças nessa política pública, tendo em vista que constitui-se como elemento basilar para que tanto as editoras produzam suas propostas a serem submetidas à apreciação, avaliação, aprovação (ou reprovação) e posterior escolha e aquisição pelo Estado e, também, constitui-se como subsídio que baliza o processo de avaliação destas obras pelas equipes de avaliação compostas por professores da educação básica e educação superior dos diversos componentes curriculares.

Tendo essa consciência, neste texto, a proposta é analisar em que medida os editais mais recentes do PNLD têm contribuído para manter e para fortalecer a perspectiva cidadã, considerando que este constitui-se caminho possível para a formação de sujeitos mais conscientes, críticos, participativos e empáticos.

Numa dimensão mais ampla, segundo Pinsky e Pinsky (2012), cidadania é expressão concreta do exercício da democracia. Carvalho (2015), explica que a ideia de cidadão pleno corresponde à necessidade de que seja titular dos três direitos: sociais, políticos e civis. Dessa forma, ser cidadão em uma sociedade democrática requer a implementação dos três direitos. Conforme Araújo (2008, p. 77), “de um modo geral, o conceito de cidadania diz respeito à qualidade do cidadão, isto é, do indivíduo pertencente a um estado livre, no gozo dos seus direitos civis e políticos e sujeito a todas as obrigações inerentes a essa condição”.

Nesse sentido, o acesso aos conhecimentos, possível pelo livro didático, pode contribuir ao processo de formação dos estudantes sob uma perspectiva cidadã, uma vez que entende-se que por meio dos conteúdos e temas abordados pode-se construir uma compreensão de diferentes assuntos, relacionando a dimensão científica e escolar com as realidades de vida de distintos grupos. Estes grupos, por vezes, são representados ou até mesmo apresentados nos livros didáticos, outros, no entanto, não são visibilizados, o que requer que sejam considerados nos estudos propostos. Outra necessidade diz respeito à relação entre o conteúdo curricular, a proposta do livro didático e a realidade dos sujeitos onde esse recurso está sendo utilizado, o que contribui para uma maior significação dos conhecimentos. 
No intuito de analisar a perspectiva cidadã, foram selecionados os editais do PNLD 2020 (anos finais do EF), PNLD 2021 (Ensino Médio) e PNLD 2023 (anos iniciais do EF) a fim de problematizar, neste primeiro momento, alguns aspectos gerais, os quais contribuem para compreender critérios gerais a serem seguidos pelas editoras.

O edital do PNLD 2020 menciona como critério comum a todas as coleções a observância aos princípios éticos necessários à construção da cidadania e ao convívio social republicano. Dentre os critérios para a cidadania e o convívio social republicano indica que a obra deve:

- Estar livre de estereótipos ou preconceitos de condição socioeconômica, regional, étnico-racial, de gênero, de orientação sexual, de idade, de linguagem, religioso, de condição de deficiência, assim como de qualquer outra forma de discriminação, violência ou violação de direitos humanos.

- Promover positivamente a cultura e a história afro-brasileira, quilombola, dos povos indígenas e dos povos do campo, valorizando seus valores, tradições, organizações, conhecimentos, formas de participação social e saberes.

- Precisa representar a diversidade cultural, social, histórica e econômica do país, e considerar as diferenças políticas, econômicas, sociais e culturais de povos e países.

- Promover condutas voltadas para a sustentabilidade do planeta, para a cidadania e o respeito às diferenças.

No edital do PNLD 2021, considera como critérios gerais:

- Estar livre de estereótipos ou preconceitos de condição socioeconômica, regional, étnico-racial, de gênero, de orientação sexual, de idade, de linguagem, de deficiência, religioso, assim como de qualquer outra forma de discriminação, violência ou violação de direitos humanos.

- Não expressar qualquer forma de doutrinação religiosa, política ou ideológica e promover o pluralismo de ideias.

- Promover positivamente a imagem de afrodescendentes e indígenas e também das mulheres, considerando sua participação em diferentes trabalhos, profissões e espaços de poder.

- Considerar a cultura e a história afro-brasileira, quilombola, dos povos indígenas e dos povos do campo, afim de valorizar seus saberes, conhecimentos, tradições, organizações, valores e formas de participação social.

- Representar a diversidade social, histórica, política, econômica, demográfica e cultural do Brasil com o intuito explícito de subsidiar a análise crítica, criativa e propositiva da realidade brasileira. 
- Representar as diferenças sociais, históricas, políticas, econômicas, demográficas e culturais de outros povos e países com o intuito explícito de subsidiar a análise crítica, criativa e propositiva da realidade brasileira em comparação com o resto do mundo.

- Promover práticas (orais e escritas) de argumentação considerando dados científicos a respeito dos princípios éticos necessários à construção da cidadania e ao convívio social republicano.

No PNLD 2023, destinado aos anos iniciais, chama a atenção a mudança nos aspectos gerais, dentre os quais destaca-se os seguintes:

- Respeitar todos os brasileiros e a liberdade de consciência, a liberdade religiosa e a liberdade política dos alunos e de suas famílias, observado o caráter laico do Estado e o respeito ao sentimento religioso.

- Promover positivamente a imagem dos brasileiros, homens e mulheres, e valorizar as matrizes culturais do Brasil - indígena, europeia e africana - incluindo as culturas das populações do campo, afrobrasileira e quilombola.

- Promover valores cívicos, como respeito, patriotismo, cidadania, solidariedade, responsabilidade, urbanidade, cooperação e honestidade.

- Representar a diversidade cultural, social, histórica e econômica do país nos textos, enfoques e exemplos utilizados nas obras, evidenciando a contribuição de diferentes povos na formação do Brasil e suas regiões;

- Promover condutas voltadas para a sustentabilidade do planeta, para a cidadania e o respeito às diferenças.

- Estar livre de preconceitos ou discriminações de qualquer ordem, de qualquer forma de promoção da violência ou da violação de direitos humanos;

Como é possível observar, os editais trazem a visibilidade de aspectos que contribuem à formação cidadã e princípios essenciais à convivência social. No entanto, o edital 2023 traz alterações significativas no que tange a aspectos específicos que anteriormente eram visíveis e valorizados como avanços conquistados. Dentre os aspectos que sofreram mudanças pode-se destacar: a não violência contra a mulher, a igualdade de gênero, o respeito e a valorização de povos historicamente discriminados, como indígenas e negros.

Outro elemento que chama a atenção é a pouca ênfase aos tipos de violência, às formas de preconceito e às discriminações, temas que anteriormente eram inseridos em edital de forma que levasse às editoras à produção de obras didáticas que trouxessem de forma explícita a possibilidade de combate a tais situações. 
É necessário considerar que, mesmo que nos editais apresentem os elementos a serem considerados na formulação de propostas didáticas, as editoras constroem suas propostas da forma como consideram mais coerente, mas devem sempre respeitar o edital do PNLD. Sendo assim, não existem parâmetros de mensuração que efetivamente obriguem a uma abordagem mais completa e complexa de determinados temas nos livros didáticos. Há situações em que as editoras avançam na perspectiva cidadã, visibilizam diversidades e provocam reflexões sobre situações de violência, por exemplo. No entanto, em um contexto cuja perspectiva política é de silenciamento das diversidades e das lutas sociais empreendidas por distintos grupos, acaba ocorrendo também um processo de invisibilização de temas considerados tão caros à formação dos cidadãos críticos, conscientes e empáticos.

Diante disso, a partir do nosso olhar de professores de geografia e pesquisadores que atuaram também na avaliação de livros didáticos, alguns aspectos são considerados essenciais para ampliar a perspectiva da cidadania nas propostas didáticas dos livros de geografia. um dos desafios atuais é compreender a dinâmica destes materiais, haja vista que atualmente os objetos do conhecimento da geografia têm sido propostos em coleções por área de conhecimento, estando, portanto, junto a outros componentes curriculares das Ciências Humanas e Sociais Aplicadas. Tais propostas formam coleções por área do conhecimento, ou, ainda, coleções que dialogam com outros campos do conhecimento.

Tal mudança visou a adequação das coleções didáticas à Base Nacional Comum Curricular, implementada em 2018. As mudanças nas coleções do PNLD podem ser consideradas como o primeiro grande impacto na vida dos docentes da educação básica, que distantes de grande parte das discussões referentes à construção e implementação da BNCC, passam a vê-la agora de forma materializada nos livros didáticos, o que gera desafios à práxis docente.

A partir das mudanças nos editais e da própria forma e conteúdo das novas coleções, entende-se que estas podem contribuir para a qualidade da formação dos estudantes desde que sejam analisadas em suas proposições, considerando as mais variadas temáticas, o enfoque apresentado, o cuidado com as diversidades, com as diferentes formas de vida das populações, e os contextos nos quais estes materiais serão utilizados, dentre outros aspectos. Portanto, a política dos materiais didáticos precisa considerar, sob o aporte da ciência, aspectos que fortaleçam a democracia, a qualidade do conteúdo, o cuidado com os distintos sujeitos e contribuir para a formação de sujeitos que exerçam a cidadania de forma ativa, consciente e colaborativa. 
Este tipo de posição se torna ainda mais latente em um mundo de rápidas mudanças e em que se convive com diferentes facetas do racismo e do negacionismo. A educação por si só não modifica as estruturas da sociedade, mas ela, no coletivo de professores, funcionários de escola, estudantes e outros sujeitos envolvidos nos processos educativos, é parte importante na mudança de pensamento para a construção de um outro mundo possível, um mundo que se paute na partilha, no coletivo e em outras formas de integração social que não as que vivemos sobre a égide da mão invisível do mercado.

Nesse sentido, escolher um material didático que contribua para a cidadania envolve, para além de conteúdos específicos e aspectos gerais para a convivência democrática, como pode ser a sua utilização na construção de sujeitos conscientes, críticos, empáticos e que atuem na tomada de decisões e no delineamento de proposições para o futuro do país. Este constituise como elemento a ser debatido no tópico a seguir, ao pensar a construção da cidadania a partir da geografia e por meio de contribuições do livro didático.

\section{O LIVRO DIDÁTICO DE GEOGRAFIA E A CONSTRUÇÃO DA CIDADANIA}

Problematizar a permanência dos livros didáticos nas escolas e sua pertinência no contexto da atuação dos professores de geografia envolve considerar as possibilidades de contribuição e, ao mesmo tempo, a atenção a determinados critérios relacionados aos limites destes materiais, tendo em vista que por melhores que sejam as propostas, há sempre fragilidades e aspectos a serem complementados, repensados em seu uso.

Debater esses aspectos tem por base inúmeras razões, seja por aprofundar debates sobre até que ponto essas políticas chegam ao conhecimento dos professores, seja na formação acadêmica ou no âmbito da atuação nos contextos escolares, em que essas políticas efetivamente são (ou deveriam ser) levadas em consideração. E, também, porque, no que se refere aos livros didáticos, são investidos recursos públicos ${ }^{3}$ para avaliar, adquirir e distribuir as coleções didáticas de todas as grandes áreas do conhecimento, para que sejam disponibilizadas aos estudantes e professores e contribuam com a aprendizagem escolar.

Uma das preocupações consideradas em nossas pesquisas é entender como o livro didático, que apresenta as categorias, conceitos e conteúdos específicos da geografia, pode

\footnotetext{
${ }^{3}$ Segundo Mello (2012), em 2011 o faturamento da indústria editorial foi de mais de 1 milhão de reais, valor oriundo apenas do governo federal. Na última década estes valores aumentaram significativamente, tendo valores públicos destinados a distintos grupos editoriais privados que submetem suas propostas para os distintos editais do PNLD.
} 
contribuir para a construção de processos educativos voltados à formação cidadã, a partir de aportes da ciência geográfica, tomada em seu caráter escolar, ou seja, contribuindo para a formação dos estudantes que passam pela educação formal. Nesse sentido, pensar o ensino de geografia remete tanto à formação qualificada de professores, quanto aos investimentos nas propostas dos recursos didáticos, dentre eles os livros didáticos.

Considerando que nosso enfoque é o livro didático, o desafio é compreender em que medida pode contribuir com o trabalho do professor e como pode ser melhorado para atender as diversidades e ao abordar as desigualdades evidenciadas no Brasil.

A atenção dos professores aos livros didáticos, nesse processo, não se refere à defesa de que utilizem frequentemente esse materual, como um manual a ser seguido rigidamente. $\mathrm{O}$ fato é que, além de se constituir como um direito dos alunos de acesso ao conjunto de conteúdos a ser disponibilizado a fim de construir conhecimentos a partir do que foi produzido pela humanidade ao longo do tempo, também constitui-se de um material, que mesmo com controvérsias em relação aos investimentos públicos ${ }^{4}$, passa por uma avaliação pedagógica, amparada em um edital construído pelo Ministério da Educação, o qual ampara tanto as editoras para que criem ou modifiquem suas coleções didáticas, quanto aos professores de escolas de educação básica e de instituições de ensino superior que participam como avaliadores.

É importante considerar que os professores precisam, no contato com os livros didáticos e na escolha de novas coleções, construir, em um primeiro momento, o entendimento de que a escolha não pode ser realizada apenas a partir daquelas coleções que as editoras enviam à escola. Geralmente apenas alguns grupos editoriais enviam os livros físicos às escolas, o que faz com que os professores, quando não cientes disso, escolham somente dentre estes materiais, não acessado o Guia do Livro Didático como suporte na escolha.

Nessa situação, o que precisa ser feito é acessar o site do FNDE e consultar o Guia do Livro Didático $^{5}$, que apresenta as resenhas de cada uma das coleções de livros aprovados em cada componente curricular (ou por grande área do conhecimento). Constitui-se de uma espécie de catálogo onde se pode conhecer a obra, identificar a editora, saber quais são os autores, de que forma sua proposta está estruturada (descrição de capítulos), além de conter uma análise feita pelos avaliadores com relação aos aspectos que a obra apresenta, indicando, também, alguns cuidados ao professor ao se utilizar essa coleção em sala de aula.

\footnotetext{
${ }^{4}$ Ao todo são investidos mais de um bilhão de reais a cada ano na avaliação, aquisição e distribuição de livros didáticos aos distintos níveis de ensino.

${ }^{5} \mathrm{O}$ acesso ao Guia do Livro Didático pode ser acessado no seguinte link: https://pnld.nees.ufal.br/
} 
Mais recentemente, os professores e professoras podem conseguir acesso às coleções na íntegra, a partir de uma chave de acesso ${ }^{6}$ que é disponibilizada aos diretores das instituições educacionais, que são contempladas com o PNLD. Dessa maneira, os docentes passam a ter mais uma forma de contato com as propostas dos livros didáticos.

Estes materiais podem ser escolhidos a depender da realidade escolar e do plano político-pedagógico de cada instituição. $\mathrm{O}$ acesso virtual aos livros contribui para que, além do contato com a resenha presente no Guia Digital, os professores possam acessar os conteúdos das coleções de livros didáticos e verificar quais delas mais se adequam à realidade em que atuam.

A questão que persiste é a necessidade de que os professores tenham conhecimento de que podem acessar tais coleções de forma virtual e que os diretores das instituições escolares precisam fornecer o acesso esse acesso e garantir tempo adequado para que os professores possam de forma conjunta decidir as coleções a serem adotadas.

Esse procedimento de escolha colaborativa é ainda mais importante em um contexto em que não existem mais coleções específicas para cada componente curricular, ou seja, atualmente há coleções, por exemplo, para o Componente Curricular de Ciências Humanas e Sociais Aplicadas e não mais específicos de geografia e de história. A análise conjunta entre os professores pode conduzir a um trabalho coletivo dos docentes da área e, por consequência, gera a necessidade de decisão conjunta em relação à escolha da coleção que será utilizada por todos os professores da referida área.

A relação entre o currículo escolar, os conteúdos e propostas que cada professor planeja para as suas aulas precisa ser considerada no momento de escolher a coleção que estará cotidianamente fazendo parte do trabalho do professor, seja como complemento ao processo educativo, ou, principalmente, como direito dos estudantes. Por isso, considera-se necessário que no planejamento docente e em sala de aula, ao ensinar geografia, os professores levem em conta distintas estratégias para contribuir à educação geográfica e tenha como dimensão mais ampla a formação para a cidadania, sob uma perspectiva de sociedade democrática.

Uma consideração importante se refere ao cuidado com as propostas dos materiais didáticos em sua estrutura geral (aspectos teórico-metodológicos e didático-pedagógicos). É

\footnotetext{
6 A chave de acesso pode ser inserida no link: http://simec.mec.gov.br/livros/leitorlivros/index2.php?codcolecao=0152P21204. Acesso em: 29 de dezembro de 2021. Nesse link se poderá ter acesso aos volumes da coleção "Diálogos em Ciências Humanas" da editora Ática. Outras coleções da área de Ciências Humanas e Sociais Aplicadas podem ser acessadas a partir do Guia Digital no link: https://pnld.nees.ufal.br/pnld 2021 didatico/componente-curricular/pnld-2021-obj2-ciencias-humanassociais-aplicadas. Acesso em: 29 de dezembro de 2021.
} 
necessário analisar essa perspectiva nos livros de estudante, no manual do professor e nos recursos digitais. Mas é importante também ter atenção sobre os aspectos focados nas especificidades das proposições apresentadas nos textos, ilustrações, representações cartográficas, gráficos, tabelas, textos complementares, atividades propostas e outras atividades que complementam a proposta. $\mathrm{O}$ conjunto precisa considerar as diversidades, o cuidado com a linguagem e com a proposição da construção de conhecimentos, um olhar mais amplo, complexo e conectado com o mundo e as situações que ocorrem em distintas escalas de análise (local, regional, nacional, global).

Orientações ao professor, aspectos teóricos e metodológicos, adequação e coerência com a legislação vigente e cuidados com os princípios éticos, respeito às diversidades étnicas e culturais, igualdade de gênero, respeito à condição de crianças, adolescentes e idosos, dentre outros, são essenciais para que se pense uma proposta de educação democrática, igualitária e contributiva à cidadania. Diante disso, e considerando que o livro didático é ainda hoje o recurso mais presente em sala de aula, alguns olhares precisam ser lançados com relação ao livro didático, tanto em seus aspectos físicos quanto com relação às propostas teóricas, metodológicas e pedagógicas que apresentam. Desse modo, tais aspectos são refletidos na interação com a perspectiva da cidadania:

1. A qualidade da proposta: envolve a dimensão teórico e metodológica relacionada à organização pedagógica, de modo que os conteúdos e atividades provoquem a reconhecer as diversidades, o mundo como espaço comum, e as condições de viver e sobreviver em distintos lugares e situações. Pensar uma geografia escolar sob uma proposta atenta ao mundo, às transformações socioespaciais, aos processos de ocupação, desigualdades, constitui uma necessidade que perpassa o ensino de geografia e o próprio livro didático.

Sobre essa questão, Costella (2017, p. 185-186) desenvolve uma reflexão importante:

\begin{abstract}
O que fica para nossos alunos não são os conteúdos, são as ideias produzidas a partir destes conteúdos, o que fica e o poder da síntese, e o entendimento do todo, o posicionamento, a consciência, a reflexão, o poder das relações. Não permanecerão, nas mentes dos alunos, os nomes das vegetações que compõem a Amazônia, o que permanecera e a consciência temporal da sua existência e consequentemente a relação desta temporalidade com a preservação e a luta por condições melhores daquela e de outras populações.
\end{abstract}

Os professores, na hora de decidirem qual coleção adotar, podem encontrar uma diversidade de propostas dentro do Guia Digital do Livro Didático, pois, cada autor ou cada grupo de autores pensam a partir de uma dimensão teórico-metodológica, a fim de construírem suas coleções. Assim, muitas vezes, percebem-se estruturas mais conservadoras no modo de 
apresentar as temáticas e mesmo nas propostas de atividades e reflexões a serem realizadas por parte de professores e estudantes. Mas, há por outro caminho, este perceptível em coleções que buscam provocar e construir pensamentos reflexivos, indo de encontro com o que Costella (2017) aponta em sua escrita, ao afirmar que o que fica não são os conteúdos que estão presentes nos livros didáticos, mas sim, as reflexões que dali podem ser desenvolvidas, de forma conjunta com os alunos e com os colegas professores.

Neste sentido, cada professor vai ter oportunidade de selecionar a qualidade da proposta que mais se aproxima de suas visões de mundo e também em relação à realidade escolar em que está inserido. Como um país diverso, as propostas de coleções também os são, por isso da necessidade de se analisar, com cuidado, e de forma conjunta qual coleção escolher para ser utilizada ao longo dos próximos quatro anos letivos.

2. A qualidade teórica e metodológica: o desenvolvimento dos conteúdos, o aporte científico relacionado com as realidades em distintos espaços, constituem-se como aspectos a serem considerados ao propor uma organização em que os aportes metodológicos deem conta de relacionar conceitos, categorias, informações, provocações que avancem as análises geográficas e a construção dos conhecimentos.

No momento de planejar, no ensino da Geografia na escola, esse olhar com relação aos livros possibilita perceber elementos contributivos para propor a construção de conhecimentos mais relacionados com a atuação dos estudantes como sujeitos ativos em sociedade e na própria formação. Entende-se nesse processo, que:

Leitura e interpretação são essenciais em geografia, porém, mais do que isso: é preciso relacionar, analisar, estabelecer relações, diferenciações, compreender pela leitura do espaço, em diferentes escalas, o que significa cada tema, cada conceito, cada movimento que se realiza na constante interação que realizamos em sociedade. Por vezes essas atividades parecem complexas frente à linguagem mais elaborada de alguns livros didáticos, o que torna necessário, mais uma vez a atuação do professor para mediar, com uso de outras linguagens ou diferentes recursos, a aprendizagem. Leituras de jornais, revistas, textos literários, músicas, poemas, desenhos, charges, são algumas das possibilidades de "movimentar" a aula. Estas podem servir para comparar, complementar ou até mesmo contestar determinada informação disponibilizada no livro didático (COPATTI, 2017, p. 89).

3. A qualidade didático-pedagógica: a estrutura das propostas precisa tomar como central uma linguagem que provoque o pensar sobre o mundo da vida, aquilo que cada aluno em sua realidade vivencia. Esse aspecto, tomado como ponto de partida para organizar processos que mobilizem o raciocínio, contribui para compreender temas, conceitos, conteúdos a partir de um nível cognitivo coerente coma etapa de desenvolvimento dos estudantes. Isso pode provoca-los a avançarem na construção de conhecimentos mais complexos, o que envolve 
aspectos racionais mas também a dimensão do sensível, ou seja, um processo educativo voltado a pensar os sujeitos como seres humanos em construção, em aprendizado, como seres diversos, e que, portanto, precisam ser tomados como partícipes da sociedade e do próprio processo formativo.

4. A qualidade argumentativa e problematizadora: toda coleção didática de geografia precisa respeitar princípios éticos, democráticos e normativos que envolvem a legislação, os cuidados com relação à não reprodução de qualquer forma de preconceito, de racismo, de linguagem incoerente com a dimensão democrática e a cidadania. No entanto, somente apontar tais aspectos de modo superficial não é suficiente. Requer, portanto, que as propostas provoquem mudanças, o repensar sobre a atuação social (ou a não atuação) e contribuem para um maior envolvimento a partir das análises socioambientais e da participação no intuito de provocar mudanças, exercendo a cidadania ativa.

Santos (2018, p. 107), considera que:

O professor, seja de Geografia, seja de outra área de conhecimento, precisa se colocar em movimento, partir dos saberes espaciais de seus alunos para propor problemas geográficos que precisam ser pensados, refletidos, debatidos e resolvidos dentro do contexto de aprendizagem dos conteúdos dos currículos escolares, permitindo que o aluno compreenda suas práticas espaciais e os pontos de vista de seus colegas e familiares, e, principalmente de outros povos que juntos a ele formam a sociedade humana.

O livro didático se constitui a partir de certas concepções e conteúdos construídos a partir de um "recorte" de conhecimentos disponíveis, em um formato adequado à escola e ao contexto escolar, podendo servir como um suporte de conhecimentos escolares, métodos pedagógicos, como veículo de divulgação de valores e como uma mercadoria. Assume, portanto, diferentes funções, dentre elas, segundo Callai (2013), oportuniza, ao ser disponibilizado em todo o país, a democratização do acesso ao conhecimento, e como tal, é uma poderosa ferramenta que pode servir para a construção da cidadania.

Para que isso se consolide de uma forma mais explícita, se torna imperativo o desenvolvimento de um pensar que refute as condições que estruturam um processo de ensino e aprendizagem tradicional. Sendo assim, provocar que os estudantes compreendam suas práticas espaciais e de seus iguais somente é possível a partir de uma visão crítica dos temas que são apresentados nos cotidianos escolares, o que se torna imperioso para se ter uma real construção do que se chama cidadania. Passa pelas escolas, pelas interações em sala de aula, a possibilidade de construir uma posição problematizadora diante do que é proposto aos estudantes. 
Essa posição de se problematizar as questões juntamente com a democratização do acesso ao conhecimento, apontado por Callai (2013), colabora para a construção de uma escola e uma sociedade com maior justiça social. Sendo assim, entende-se que o Programa Nacional do Livro e do Material Didático se constitui como uma política pública importante e necessária, mas que somente se efetiva em sua potencialidade à medida que os aspectos que envolvem democracia, cidadania e construção da consciência crítica dos sujeitos sejam efetivados.

Para tanto, a atuação dos professores na análise das propostas dos livros, na escolha de coleções que contribuam à realidade em que atuam, são aspectos essenciais para que se possa, cada vez mais, garantir uma educação de qualidade, sendo esta, uma via para a atuação cidadã de nossos estudantes.

\section{CONSIDERAÇÕES FINAIS}

A política nacional do livro e do material didático vai muito além dos processos de produção, avaliação, escolha e distribuição de coleções didáticas, envolve as situações cotidianas nas escolas que se relacionam a estes materiais e tem uma perspectiva maior, a qual se refere à contribuição para a cidadania.

Frente ao contexto atual de investimentos significativos em materiais didáticos, os debates acerca da sua utilização e dos processos envolvidos na relação destes com a escola e a realidade dos estudantes se faz necessária. O livro didático enquanto política pública denota distintas interpretações, tendo em vista que serve para democratizar o acesso a um recorte de conhecimentos aos estudantes, principalmente das escolas públicas conveniadas.

O livro didático, apesar de ser bastante debatido e questionado, é tido como um recurso que democratiza o acesso ao conhecimento, tendo em vista que, em muitas escolas, não há outros materiais que sirvam de modo mais efetivo como fonte de pesquisa, de informação e para a construção de conhecimento. Dessa forma, contribuem para que os estudantes e seus professores tenham acesso a um conjunto de recursos que possam complementar o processo educativo.

É preciso, ao conhecer esse material e a sua dimensão enquanto política pública, afastar as perpectivas de senso comum que permeiam o livro didático, principalmente dentro da formação inicial de professores. Tal processo leva a compreender a presença desse recurso na sala de aula e evita os silenciamentos tão frequentes relativos à presença desse material e ao seu uso. 
Muitas percepções negativas permanecem sobre este material, desconsiderando, muitas vezes, as realidades das escolas, dos professores e dos estudantes, ou mesmo, os pontos positivos que acompanham todo o processo de construção e uso dos livros didáticos. Neste sentido, se torna importante conhecer o que está presente nos editais construídos pelo MEC e que regem todo o processo existente no PNLD, até mesmo para que tenhamos uma maior apropriação deste processo. Ainda, para que, a partir disso, seja possível tecer críticas mais contundentes com relação aos aspectos que não estão de acordo com a perspectiva de formação cidadã, necessária à educação brasileira.

Considerando isso e procurando tecer aproximações entre a política do livro didático e o ensino de Geografia, as reflexões a partir dos editais Programa Nacional do Livro e do Material Didático (PNLD 2020, PNLD 2021, PNLD 2023) permitiram identificar aspectos que envolvem a perspectiva da cidadania, os quais podem contribuir ao ensino escolar de geografia.

Elementos referentes ao conteúdo, aspectos metodológicos, qualidade gráfica, propostas de atividades, textos complementares, links para acesso, precisam convergir para a perspectiva de formação para a cidadania, relacionando conhecimentos científicos e escolares, no intuito de repensar realidades e propor o exercício ativo da cidadania no sentido de provocar mudanças sociais.

\section{REFERÊNCIAS}

BRASIL. Ministério da Educação. Fundo Nacional de Desenvolvimento da Educação. Secretaria de Educação Básica. Edital de Convocação no 01/2021 - CGPLI. Edital de Convocação para o Processo de Inscrição e Avaliação de Obras Didáticas, Literárias e Pedagógicas para o Programa Nacional do Livro e do Material Didático - PNLD 2023. Brasília, 2021.

BRASIL. Ministério da Educação. Fundo Nacional de Desenvolvimento da Educação. Secretaria de Educação Básica. Edital de Convocação nº 03/2019 - CGPLI. Edital de Convocação para o Processo de Inscrição e Avaliação de Obras Didáticas, Literárias e Recursos Digitais para o Programa Nacional do Livro e do Material Didático - PNLD 2021. Brasília, 2019.

BRASIL. Ministério da Educação. Fundo Nacional de Desenvolvimento da Educação. Secretaria de Educação Básica. Edital de Convocação 01/2018 - CGPLI. Edital de Convocação para o Processo de Inscrição e a Avaliação de Obras Didáticas e Literárias para o Programa Nacional do Livro e do Material Didático - PNLD 2020. Brasília, 2018.

CALLAI, Helena C. O livro didático no contexto dos processos de avaliação. OKARA: Geografia em debate, v.10, n. 2, p. 273-290, 2016. Disponível em: https://webcache.googleusercontent.com/search?q=cache:20p6Lu6x9G4J:https://periodicos3. 
ufpb.br/index.php/okara/article/download/31203/16316+\&cd=1\&hl=pt-BR\&ct=clnk\&gl=br. Acesso em: 10, jan. 2022.

COPATTI, Carina. Livro didático de geografia: da produção ao uso em sala de aula. Élisée, Rev. Geo. UEG - Porangatu, v.6, n.2, p.74-93, jul./dez. 2017. Disponível em:

https://www.revista.ueg.br/index.php/elisee/article/view/6634. Acesso em: 18, jan., 2022.

COSTELLA, Roselane Zordan. Nas entrelinhas do Livro Didático: a voz e a visibilidade do aluno. In: TONINI, Ivaine Maria; GOULART, Ligia Beatriz; SANTANA FILHO, Manoel Martins de; MARTINS, Rosa Elisabete Militz Wypyczynski; COSTELLA, Roselane Zordan (Org.). O Livro Didático de Geografia e os desafios da docência para aprendizagem. Porto Alegre: Sulina, 2017, p. 177-190.

GONÇALVES, Paulo Celso Costa. Políticas públicas de livro didático: elementos para compreensão da agenda de políticas públicas em educação no Brasil. [Tese]. Programa de Pós-Graduação em Educação da Universidade Federal de Uberlândia - UFU, Minas Gerais, 2017.

PINSKY, Jaime. PINSKY, Carla Bassanezi. História da cidadania. (orgs.). 6 ed. São Paulo: Editora Contexto, 2012.

SANTANA FILHO, Manoel Martins de. Sobre o Livro Didático de Geografia e os dilemas na prática docente. In: TONINI, Ivaine Maria; GOULART, Ligia Beatriz; SANTANA FILHO, Manoel Martins de; MARTINS, Rosa Elisabete Militz Wypyczynski; COSTELLA, Roselane Zordan (Org.). O Livro Didático de Geografia e os desafios da docência para aprendizagem. Porto Alegre: Sulina, 2017, p. 239-258.

SANTOS, Leonardo Pinto dos. Uma viagem geográfica pela Literatura: uma experiência com um clube do livro na Geografia Escolar. In: Revista Tamoios. São Gonçalo (RJ), ano 14, n. 1, p. 98-110, jan-jun. 2018. Disponível em: <http://www.e-

publicacoes.uerj.br/ojs/index.php/tamoios/article/view/31135>. Acesso em: 13 de jan, 2022.

SPOSITO, Maria Encarnação Beltrão. A avaliação de livros didáticos no Brasil - por quê? In: SPOSITO, Maria Encarnação Beltrão (Org.). Livros didáticos de História e Geografia: avaliação e pesquisa. São Paulo: Cultura Acadêmica, 2006, p. 15-25.

Artigo recebido em: 31 de dezembro de 2021.

Artigo aceito em: 20 de de fevereiro de 2022.

Artigo publicado em: 21 de fevereiro de 2022. 